\title{
The status of General Binocular Dysfunctions among School Children
}

\author{
Jung Un Jang ${ }^{1 \star}$ and Jung Yun Jang ${ }^{2}$ \\ ${ }^{1}$ Department of Optometry, Eulji University, Seongnam, South Korea \\ ${ }^{2}$ Department of Physical education and health, Jeollanamdo office of education, Jeollanamdo, South Korea
}

\section{Article Info}

*Corresponding author:
Jung Un Jang
Department of optometry
Eulji University
Seongnam
553 Sangseong -daero Sujeong gu
Seongnam si Gyeonggi do 461-713
South Korea
E-mail: jju@eulji.ac.kr

Received: October 13, 2017

Accepted: November 30, 2017

Published: December 5, 2017

Citation: Jang JU, Jang JY. The status of General Binocular Dysfunctions among School Children. Madridge J Ophthalmol. 2017; 2(1): 22-25.

doi: $10.18689 / m j o p-1000107$

Copyright: ( $\odot 2017$ The Author(s). This work is licensed under a Creative Commons Attribution 4.0 International License, which permits unrestricted use, distribution, and reproduction in any medium, provided the original work is properly cited.

Published by Madridge Publishers

\begin{abstract}
Purpose: To assess the prevalence of non-strabismic accommodative and binocular dysfunctions among elementary school children in a rural area (illo-eup) of South Korea.

Methods: We examined 335 elementary school children (all 8-13 years of age) were given a thorough eye examination including binocular vision testing to determine any form of refractive, accommodative, or binocular dysfunctions.

Results: $15.8 \%$ of the subjects presented general binocular dysfunctions. of the 53 subjects, $4.8 \%$ presented accommodative dysfunctions, and $9.3 \%$ presented vergence dysfunctions. In $4.8 \%$ of accommodative dysfunction cases, accommodative insufficiency was the most prevalent (3.0\%). In 9.3\% of vergence dysfunction cases, convergence insufficiency was the most prevalent $(7.8 \%)$.

Conclusion: Accommodative and non-strabismic binocular dysfunctions are prevalent in Korean elementary school children, especially convergence insufficiency was the most prevalent. Thus, it is important to diagnose and treat general binocular dysfunctions properly through an accurate and precise eye tests.
\end{abstract}

Keywords: Binocular dysfunctions; Accommodative dysfunctions; Vergence dysfunctions; Elementary school children.

\section{Introduction}

Accommodative and binocular anomalies tend to cause difficulties with activities requiring close vision work [1]. Defects in schoolchildren's accommodation may cause problems with specifically difficulty in reading or in learning progress [2]. There is some indication that certain binocular anomalies, such as convergence insufficiency, are related to reading problems [3]. In addition, various studies have suggested that accommodative and non-strabismic binocular dysfunctions are commonly founded $[4,5]$. These dysfunctions are commonly of associated symptoms, including blurred vision, difficulty in focusing at different distances, headache and ocular pain, and difficulty with focusing particularly when reading and writing [6]. However, the symptoms that the subjects perceives may differ depending on the type of causative disorder [7]. The aim of this study is to assess prevalence of general binocular dysfunctions among school children in South Korea.

\section{Subjects and Methods}

Illro-eup, with an area of 56.31 square kilometers, is a smallest rural town in South Jeolla province with a population were 7,814(2016), located in southeast South Korea. Illro-eup is 340.80 kilometers far from Seoul city. The illo-eup was chosen for this study, 
because the illro-eup has higher proportion of farming than that of Seoul. Seoul know well has an urban education environment. Even though, geographically, Seoul has 601 of elementary school while illro-eup the 2 elementary school.

A population aged $8 \sim 13$ was recruited from two different elementary schools, who want a participated this study in illoeup, South Jeolla Province South Korea, between December 2015 and November 2016. Samples were collected from the schoolchildren who had no history of eye injuries and who were not taking any medications. Also, none of the schoolchildren had any eye diseases, strabismus, or amblyopia that may affect the visual acuity and refractive status. All participants' parents provided written agreement forms.

The examination included the following tests:

1. A case-history: full scope of questionnaires about symptoms was asked.

2. Preliminary tests: distance and near visual acuity, distance and near cover test, near point of convergence (Fixation stick, Bernell, USA), distance and near pupillary distance (PD-85, Vitzro, Korea), ocular motility, fusion (Worth 4-dot, Bernell, USA), and stereopsis (Titmus stereo fly, Bernell, USA).

3. Assessment of refractive error: Refractive errors was determined by auto-refractor (HRK-8000A, Huvitz, Korea), and subjective refraction using phoropter (DU-7000, Korea) and auto chart projector (CCP-3100, Huvitz, Korea). Subjective refraction was performed by monocular fogging method with cross-cylinder, and followed by binocular balancing to a standard endpoint of maximum plus for best visual acuity (BVA).

4. Accommodative and binocular vision system: To assess the quality of general binocular vision system, the tests were performed with the subjective refraction in place. The von Graefe technique was used to determine phoria at near and at distance. Positive and negative fusional vergence was measured using prism bar method. AC/A ratio (accommodative convergence/ accommodation ratio) were measured using the gradient method. Positive and negative relative accommodation were determined by phoropter (DU-7000, Korea) with auto chart projector (CCP-3100, Huvitz, Korea) at $40 \mathrm{~cm}$, monocular and binocular accommodative facility was measure with $\pm 2.00 \mathrm{D}$ flipper. Near point of convergence (NPC) was evaluated by the standard push-up technique.

All tests were done three times repeatedly and recorded and the average value was analyzed. General binocular dysfunctions were classified and compared with Scheiman and Wick's classification criteria (2002) that are presented in Table 1. Participants who revealed symptoms of refractive errors and corrected with prescription glasses were classified as refractive errors.
Table 1. classification criteria for general binocular dysfunctions

Binocular vision disorders

Convergence Insufficiency

1. Symptoms associated with reading

2. Sings:

Moderate to high exophoria at near $>6 \triangle$

Low AC/A ratio (less than $3 / 1$ )

Reduced positive fusional vergence at near

Receded nearpoint of convergence

Basic Exophoria

1. Symopoms associated with distance and near tasks

2. Signs:

Exophoria of approximately equal magnitude at near and at distance Normal AC/C ratio (4/1 with a SD of \pm 2$)$

Reduced positive fustional vergence at distance and near

Basic Esophoria

1. Symptoms associated with distance and near tasks

2. sings:

Esophoria of approximately equal magnitude at near and at distance

Normal AC/C ratio (4/1 with a SD of \pm 2$)$

Reduced negative fusional vergence at distance and near

Fusional Vergence Dysfunction

1. Symptoms associated with reading

2. Signs:

Orthophoria at distance and near, or a low degree of exophoria or esophoria at distance and near

Normal AC/A ratio (4/1 with a SD of \pm 2 )

Reduced negative and positive fusional vergence at distance and near

Convergence Excess

1. Symptoms associated with reading

2. Signs:

Significant esophoria at near $>2 \triangle$

High $A C / C$ ratio (greater than $7 / 1$ )

Reduced negative fusional vergence at near

Accommodative Anomalies

Accommodative insufficiency

1. Symtoms associated with reading

2. Signs:

Push-up accommodative amplitude at leat $2 \mathrm{D}$ below

Hofstetter;s calculation for minimum age-appropriate amplitude: 15 $-0.25 x$ age in years

Decreased positive relative accommodation, $\leq 1.25 \mathrm{D}$

Difficulty clearing $-2.00 \mathrm{D}$ with monocular and binocular accommodative facility (monocular $\leq 4.5 \mathrm{cpm}$, binocular $\leq 2.5 \mathrm{cpm}$ )

Accommodative Infacility

1. Symptoms associated with reading

2. Signs:

Difficulty clearing $-2.00 \mathrm{D}$ and $+2.00 \mathrm{D}$ with monocular and vinocular accommodative facility (monocular $\leq 4.5 \mathrm{cpm}$, binocular $\leq 2.5$

Low positive and negative relative accommodation, PRA $\leq 1.25 \mathrm{D}$ and NRA $\leq 1.50 \mathrm{D}$

Accommodative Excess

1. Symptoms associated with reading

2. Sings:

Variable static and subjective

Possibly low degree of against-the-rule cylinder

Variable visual acuity findings

Difficulty clearing $+2.00 \mathrm{D}$ with monocular and binocular accommodative facility (monocular $\leq 4.5$

$\mathrm{cpm}$, binocular $\leq 2.5 \mathrm{cpm}$

Low NRA $<1.50 \mathrm{D}$

\section{Data Analysis}

All data was entered into a Microsoft Excel database. Analyses were conducted, followed by frequencies, percentage using SPSS (version 21.0 for Windows, SPSS Inc., Chicago, IL). 


\section{Informed Consent and Ethical Approval or Procedures}

The local Administration of the Education and School Board were contacted to request their cooperation. After securing permission to perform the study, approval was obtained by the appropriate university ethical advisory committee. Completed consent forms were obtained from the parents or guardians of all children were obtained before the examination.

\section{Results}

The Characters of subjects are summarized in Table 2.

Table 2. Characteristics of subjects

\begin{tabular}{lll}
\hline & $n$ & $\%$ \\
\hline Emmetropia & 55 & 16.4 \\
\hline Refractive error & 217 & 64.8 \\
\hline Strabismus & 3 & 0.9 \\
\hline amblyopia & 5 & 1.5 \\
\hline None examinable & 2 & 0.6 \\
\hline Binocular dysfunctions & 53 & 15.8 \\
\hline Total & 335 & 100 \\
\hline
\end{tabular}

of 335 subjects, $64.8 \%$ presented some kind of refractive errors, and $16.4 \%$ presented emmetropia. $15.8 \%$ of the subjects (53 subjects) presented binocular dysfunctions and met the criteria for this study (Table 1). In this study, only subjects with abnormal symptoms were considered as prevalence of binocular dysfunctions. A breakdown of these results is given in Table 3. of 53 subjects with general binocular dysfunctions, 4.8\% (16 subjects) presented accommodative dysfunctions and 9.3\% (31 subjects) presented vergence disorders. $1.8 \%$ (6 subjects) had binocular dysfunctions which were combined accommodative and vergence dysfunctions. As can be seen in Table 3, a greater prevalence of accommodative insufficiency (3.0\%) was revealed, followed by accommodative infacility (1.5\%). Also, convergence insufficiency was the most prevalent (7.8\%), followed by basic exophoria (0.9\%), and convergence excess (0.6\%).

Table 3. Prevalence of general binocular dysfunctions

\begin{tabular}{lll}
\hline Classification & $n$ & $\%$ \\
\hline Binocular dysfunctions & 53 & 15.8 \\
\hline Accommodative Dysfunctions & 16 & 4.8 \\
\hline \multicolumn{1}{c}{ Accommodative insufficiency } & 10 & 3.0 \\
\hline Accommodative infacility & 5 & 1.5 \\
\hline Accommodative excess & 1 & 0.3 \\
\hline Vergence dysfunctions & 31 & 9.3 \\
\hline Convergence insufficiency & 26 & 7.8 \\
\hline Basic exophoria & 3 & 0.9 \\
\hline Convergence excess & 2 & 0.6 \\
\hline Combined accomodation and vergence dysfunctions & 6 & 1.8 \\
\hline Combined accomodation and convergence insufficiency & 4 & 1.2 \\
\hline Combined accomodation excess and convergence insufficiency & 2 & 0.6 \\
\hline Emmetropia & 55 & 16.4 \\
\hline Refractive error & 217 & 64.8 \\
\hline Strabismus & 3 & 0.9 \\
\hline amblyopia & 5 & 1.5 \\
\hline None examinable & 2 & 0.6 \\
\hline Total & 335 & 100 \\
\hline
\end{tabular}

of $19.8 \%$ subjects, various symptoms were presented. The principal symptoms among the subjects were asthenopia, including asthenopia toward the end of the day (11.7\%), followed by headache, including headache toward the end of day (3.9\%). In addition, $1.8 \%$ of the subjects presented blurred vision at distance, $1.5 \%$ of the subjects presented intermittent diplopia, and $0.9 \%$ of the subjects presented intermittent blurred vision at near (Table 4).

Table 4. Prevalence symptoms of students.

\begin{tabular}{lll}
\hline Symptoms & $n$ & $\%$ \\
\hline Asthenopia after 1 or $2 \mathrm{~h}$ & 24 & 7.2 \\
\hline Asthenopia toward end of day & 15 & 4.5 \\
\hline Headache & 9 & 2.7 \\
\hline Headache toward end of day & 4 & 1.2 \\
\hline Blurred vision at distance & 6 & 1.8 \\
\hline Intermittent blurred near vision & 3 & 0.9 \\
\hline Intermittent diplopia & 5 & 1.5 \\
\hline No symptoms & 269 & 80.2 \\
\hline Total & 335 & 100 \\
\hline
\end{tabular}

\section{Discussion}

Eye anomalies can be classified as visual efficiency anomalies, such as accommodative and/or vergence disorders, and visual information process anomalies, such as anomalies of cognitive function and perception $[4,15,16]$. A number of reports on the prevalence of accommodative and vergence dysfunctions were done with various diagnostic criteria, special characteristics of the populations, and the study different area and age [8-12].

This study was performed in a rural region in south Jolla province (illro-eup) of South Korea.

In our study, $15.8 \%$ of rural elementary school students presented with general binocular dysfunctions. The overall prevalence of binocular dysfunctions was $15.8 \%$, also vergence dysfunctions (9.3\%) were more prevalent than accommodative dysfunctions (4.8\%), especially, convergence insufficiency (7.8\%) was more prevalent than accommodative insufficiency (3.0\%).

The present study was 119 symptomatic subjects, aged 4-35 years, and found $21 \%$ of patients presented general binocular dysfunctions. Also, of 25 patients, $16.8 \%$ presented accommodative dysfunctions and $4.2 \%$ presented vergence disorders [13]. According to Hennessey et al. of randomly selected children, aged 8-14, who had comprehensive screening tests, the prevalence of symptomatic accommodative infacility was $23.3 \%$ [14]. In a study of optometry students, found the prevalence of accommodative dysfunctions was $17 \%$ and the prevalence of vergence disorders was $15.3 \%$ [12]. Also, in a study of clinic patients found the prevalence of accommodative dysfunctions was $9.4 \%$ and a vergence disorder was $12.9 \%$ [8].

On study also shows that accommodative insufficiency was the most prevalent, followed by accommodative infacility (9.3\% and $5 \%$ respectively), and accommodative excess was the most prevalent, followed by convergence insufficiency (10.8\% and $7.7 \%$ respectively) $[12,13]$.

Beside, convergence excess was the most prevalent, followed by accommodative excess ( $9 \%$ and $6.4 \%$ respectively) [8]. However, in this study, convergence insufficiency was the most prevalent, followed by accommodative insufficiency (7.8\% and $3.0 \%$ respectively). In addition, the prevalence of combination of convergence insufficiency with accommodative 
insufficiency was significant (1.8\%). Several studies have been conducted on binocular dysfunctions at various ages. Those of studies also showed the similar frequency as this study.

This means that the high probability of occurrence of binocular dysfunctions during school age, also showed convergence insufficiency and accommodative insufficiency were common conditions in school age children. Moreover, vergence disorder was the most prevalent because the subject of study was school children who need extensive amount of near work during studying and learning. Even though who lives rural area, students spend more time in studying than the other age. These findings suggest that in school children it is important to give a thorough eye examination including tests for binocular vision to detect general binocular dysfunctions. Also, it is necessary to have thorough eye examination to find an appropriate treatment plan for symptomatic subjects to improve their vision efficiency and daily lives.

\section{Conclusion}

The prevalence of general binocular dysfunctions of Korean elementary school children was $15.8 \%$. Binocular dysfunctions commonly occur for school children and have a negative influence on academic ability. Therefore, it is necessary to have an accurate tests to detect accommodative and/or vergence disorders. Also, it is recommended to have binocular function test for different age groups to compare general binocular dysfunctions in Korean population in the future.

\section{References}

1. Cacho MP, Garcia MA, Ruiz-Cantero MT. Treatment of accommodative and nonstrabismic binocular dysfunctions: A systematic review. Optometry. 2009; 80(12): 702-716. doi: 10.1016/j.optm.2009.06.011

2. Sterner B, Gellerstedt M, Sjostrom A. Accommodation and the relationship to subjective symptoms with near work for young school children. Ophthalmic Physiol Opt. 2006; 26(2): 148-155. doi: 10.1111/j.1475-1313.2006.00364.x

3. Simons HD, Grisham JD. Binocular anomalies and reading problems. J Am Optom Assoc. 1987; 58(7): 578-587.

4. Cacho P, García A, Lara F, Seguí MM. Diagnostic signs of accommodative insufficiency. Optom Vis Sci. 2002; 79(9): 614-620.

5. Borsting E, Rouse MW, De Land PN. Prospective comparison of convergence insufficiency and normal binocular children on CIRS symptom surveys. Convergence Insufficiency and Reading Study (CIRS) group. Optom Vis Sci. 1999; 76(4): 221-228.

6. Marran LF, De Land PN, Nguyen AL. Accommodative insufficiency is the primary source of symptoms in children diagnosed with convergence insufficiency. Optom Vis Sci. 2006; 83(5):281-289. doi: 10.1097/01. opx.0000216097.78951.7b

7. Cacho MP, Garcia MA, Ruiz CM. Is there any evidence for the validity of diagnostic criteria used for accommodative and nonstrabismic binocular dysfunctions? J Optom. 2014; 7(1):2-21. doi: 10.1016/j.optom.2013.01.004

8. Lara F, Cacho P, García A, Megías R. General binocular disorders: Prevalence in a clinic population. Ophthal Physiol Opt. 2001; 21(1): 70-74. doi: 10.1016/S0275-5408(99)00104-0

9. Garcia A, Cacho P, Lara F. Evaluating Relative Accommodations in General Binocular Dysfunctions. Optom Vis Sci. 2002; 79(12): 779-787.

10. Scheiman M, Gallaway M, Coulter R, Reinstein F, Ciner E, Herzberg C, et al. Prevalence of vision and ocular disease conditions in a clinical pediatric population. J Am Optom Assoc. 1996; 67(4): 193-202.

11. Robert MM. Prevalence of General dysfunctions in binocular vision. Ann Ophthalmol. 2001; 33(3): 205-208.

12. Porcar E, Martinez-Palomera A. Prevalence of general binocular dysfunctions in a population of university students. Optom Vis Sci. 1997; 74(2): 111-113.

13. Hokoda SC. General binocular dysfunctions in an urban optometry clinic. J Am Optom Assoc. 1985; 56(7): 560-562.

14. Hennessey $D$, losue $R$, Rouse MW. Relation of symptoms to accommodative infacility of school-aged children. Am J Optom Physiol Opt. 1984; 61(3): 177183.

15. Rutstein RP, Daum KM. Anomalies of accommodation. Chapter 3 in Anomalies of binocular vision: diagnosis and management. St. Louse: Mosby 1998; 61-94.

16. Scheiman, M, Wick B. Clinical Management of Binocular Vision: Heterophoric Accommodative and Eye Movement Disorders. $2^{\text {nd }}$ ed. Philadelphia: Lippincott William sand Wilkins. 2002. 